\title{
The human ABCB6 protein is the functional homologue of HMT-1 proteins mediating cadmium detoxification
}

\author{
Zsófia Rakvács ${ }^{1}$. Nóra Kucsma ${ }^{1}$ Melinda Gera ${ }^{1}$ - Barbara Igriczi ${ }^{1}$ Katalin Kiss ${ }^{1}$ - János Barna ${ }^{2}$ - Dániel Kovács ${ }^{2}$. \\ Tibor Vellai ${ }^{2}$. László Bencs ${ }^{4}$. Johannes M. Reisecker ${ }^{5} \cdot$ Norbert Szoboszlai $^{3} \cdot$ Gergely Szakács $^{1,5}$
}

Received: 30 November 2018 / Revised: 9 April 2019 / Accepted: 11 April 2019 / Published online: 3 May 2019

(c) The Author(s) 2019

\begin{abstract}
ABCB6 belongs to the family of ATP-binding cassette (ABC) transporters, which transport various molecules across extraand intra-cellular membranes, bearing significant impact on human disease and pharmacology. Although mutations in the $A B C B 6$ gene have been linked to a variety of pathophysiological conditions ranging from transfusion incompatibility to pigmentation defects, its precise cellular localization and function is not understood. In particular, the intracellular localization of ABCB6 has been a matter of debate, with conflicting reports suggesting mitochondrial or endolysosomal expression. ABCB6 shows significant sequence identity to HMT-1 (heavy metal tolerance factor 1) proteins, whose evolutionarily conserved role is to confer tolerance to heavy metals through the intracellular sequestration of metal complexes. Here, we show that the cadmium-sensitive phenotype of Schizosaccharomyces pombe and Caenorhabditis elegans strains defective for HMT-1 is rescued by the human ABCB6 protein. Overexpression of ABCB6 conferred tolerance to cadmium and As(III) $\left(\mathrm{As}_{2} \mathrm{O}_{3}\right)$, but not to $\mathrm{As}(\mathrm{V})\left(\mathrm{Na}_{2} \mathrm{HAsO}_{4}\right), \mathrm{Sb}(\mathrm{V}), \mathrm{Hg}(\mathrm{II})$, or $\mathrm{Zn}(\mathrm{II})$. Inactivating mutations of $\mathrm{ABCB} 6$ abolished vacuolar sequestration of cadmium, effectively suppressing the cadmium tolerance phenotype. Modulation of ABCB6 expression levels in human glioblastoma cells resulted in a concomitant change in cadmium sensitivity. Our findings reveal ABCB6 as a functional homologue of the HMT-1 proteins, linking endolysosomal ABCB6 to the highly conserved mechanism of intracellular cadmium detoxification.
\end{abstract}

Keywords ABC transporters · Subcellular localization · ABCB6 - HMT-1 - Endolysosomal system · Detoxification · Cadmium

Electronic supplementary material The online version of this article (https://doi.org/10.1007/s00018-019-03105-5) contains supplementary material, which is available to authorized users.

Gergely Szakács

gergely.szakacs@meduniwien.ac.at

1 Institute of Enzymology, Research Centre for Natural Sciences, Hungarian Academy of Sciences, Budapest, Hungary

2 Department of Genetics, Institute of Biology, Eötvös Loránd University, Budapest, Hungary

3 Department of Analytical Chemistry, Institute of Chemistry, Eötvös Loránd University, Budapest, Hungary

4 Institute for Solid State Physics and Optics, Wigner Research Centre for Physics, Hungarian Academy of Sciences, Budapest, Hungary

5 Department of Medicine I, Comprehensive Cancer Center, Institute of Cancer Research, Medical University of Vienna, Vienna, Austria

\section{Introduction}

ATP-binding cassette $(\mathrm{ABC})$ transporters constitute one of the largest protein families in prokaryotes and eukaryotes. $\mathrm{ABC}$ transporters are integral transmembrane proteins that function as active transporters, channels or regulators. Active ABC transporters harness the energy of ATP to move a diverse array of substrates in or out of cells, or into cellular vesicles. There are 48 human $\mathrm{ABC}$ transporters, many of which are linked to severe inherited diseases, such as cystic fibrosis, or X-linked adrenoleukodystrophy [1]. Whereas several human ABC transporters have dedicated physiological roles (e.g., transport of phosphatidylcholine by $\mathrm{ABCB} 4 / \mathrm{MDR} 3$; antigen processing by $\mathrm{ABCB} 2 / 3$ ), most recognize various xenobiotics and contribute to the "chemoimmunity" network of cells and organisms [2]. At the cellular level, multidrug resistance (MDR) transporters such as P-glycoprotein (ABCB1) play an important role in cancer 
drug resistance by reducing the concentration of chemotherapeutics below a cell-killing threshold. In addition, MDR transporters are also expressed in pharmacological barriers such as the blood-brain barrier, where they modulate the passage of drugs [3].

ABCB6 is widely expressed in many tissues, especially in the heart, liver, skeletal muscles [4], the red blood cells [5, 6], and skin [7]. ABCB6 is a half transporter of 842 amino acids, containing a unique $\mathrm{N}$-terminal region followed by the $\mathrm{ABC}$ core consisting of a transmembrane domain and a cytoplasmic nucleotide-binding domain. ABCB6 forms homodimers $[8,9]$ and was shown to possess ATPase and transport activities after purification and functional reconstitution into liposomes [10]. At present, the subcellular localization of ABCB6 remains a matter of debate. In 2006, ABCB6 was described as a mitochondrial porphyrin transporter with an essential role in heme biosynthesis [8]. Subsequent studies have found $\mathrm{ABCB} 6$ to be dispensable for erythropoiesis [5, 9], suggesting that mitochondrial porphyrin import may not depend on ABCB6. In addition, several research groups have identified $\mathrm{ABCB} 6$ in extramitochondrial compartments, challenging the paradigm linking the expression and function of ABCB6 to mitochondria. ABCB6 was detected in the plasma membrane of cells [11], the red blood cell membrane [5, 9], melanosomes [12] and throughout the endolysosomal continuum [13-17]. However, the physiological function of ABCB6 in the endolysosomal compartment has remained elusive.

ABCB6 exhibits topological and sequential similarity to HMT (Heavy Metal Tolerance) family proteins (Supplementary Table 1). HMT-1 proteins in fission yeast (Schizosaccharomyces pombe), nematode (Caenorhabditis elegans) and the fruit fly (Drosophila melanogaster) fulfill a conserved role in conferring heavy metal resistance [18-21]. In fission yeast, SpHMT-1 mediates the vacuolar sequestration of metal adducts including phytochelatin, glutathione or metallothionein complexes of heavy metal ions [18]. An elegant study from the Vatamaniuk laboratory has shown that HMT-1 proteins in C. elegans (CeHMT-1) and D. melanogaster (DmHMT-1) can also mediate the sequestration and elimination of $\mathrm{Cd}$ complexes. In particular, heterologously expressed DmHMT-1 or CeHMT-1 were shown to suppress the cadmium hypersensitivity of $S$. pombe hmt- 1 mutants, concomitant with the localization of CeHMT-1 to the vacuolar membrane. These results clearly indicated that the HMT-1-mediated detoxification of heavy metals is preserved during evolution, extending to some invertebrate species lacking the ability to synthesize phytochelatin (PC) $[20,21]$. Given the similarity of HMT-1 and ABCB6 sequences, the major aim of this study was to test if ABCB6 can complement the function of HMT-1 proteins. We show that ABCB6 can be functionally expressed in the vacuolar/ endosomal membrane, resulting in a rescue of the cadmium sensitivity phenotype of HMT-1-deficient $S$. pombe and $C$. elegans strains. Our findings reveal $\mathrm{ABCB} 6$ as a functional orthologue of the HMT-1 proteins, linking ABCB6 to the highly conserved mechanism of intracellular cadmium detoxification. Consistent with our previous findings showing extramitochondrial localization, these results provide functional evidence supporting the endolysosomal function of ABCB6.

\section{Results}

\section{Heterologous expression of human $A B C B 6$ restores cadmium tolerance of $S$. pombe hmt-1 $\Delta$ mutants}

To test whether ABCB6 and SpHMT-1 have overlapping functions, we expressed the wild-type human ABCB6 protein, a catalytically inactive mutant variant (ABCB6-KM [9]) and SpHMT-1 in a hmt-1-deleted mutant S. pombe strain showing increased cadmium (Cd) sensitivity (Fig. 1a). SpHMT-1-GFP was also localized to the vacuoles, matching the staining of the vacuolar membrane by FM 4-64 [22]. Confocal microscopy analysis of cells expressing ABCB6GFP or SpHMT-1-GFP revealed a similar intracellular pattern, indicating that the human ABCB6 protein is targeted to the yeast vacuoles (Fig. 1b). As expected, expression of SpHMT-1 fully eliminated the increased cadmium sensitivity of the $h m t-1 \Delta$ mutant strain. Expression of wild-type ABCB6 also restored cadmium tolerance, allowing transformed $S$. pombe colonies to grow in the presence of $\mathrm{Cd}(\mathrm{II})$ (Fig. 1c, Supplementary Figure 1). Rescue of hmt-1-deleted strains depended on the functionality of the heterologously expressed transporter, since an inactivating mutation affecting a conserved Walker A lysine of ABCB6 prevented the growth of $h m t$-1-deleted colonies in the presence of cadmium. Rescue was also observed in liquid medium (Fig. 1d). Cytotoxicity assays revealed that the expression of ABCB6 in $h m t-1 \Delta S$. pombe cells conferred resistance to As(III), but not to $\mathrm{As}(\mathrm{V}), \mathrm{Sb}(\mathrm{V}), \mathrm{Hg}(\mathrm{II})$, or $\mathrm{Zn}$ (II) (Supplementary Figure 2).

\section{Determination of vacuolar cadmium content}

SpHMT-1 reduces the intracellular concentrations of cadmium by catalyzing the vacuolar sequestration of $\mathrm{Cd}-\mathrm{PC}$ complexes [18]. To verify that the ability of ABCB6 to suppress the Cd hypersensitivity of HMT-1-deficient $S$. pombe mutants relies on an orthologous function, we assayed the $\mathrm{Cd}$ contents of intact vacuoles isolated from $\mathrm{CdCl}_{2}$-treated yeast cells. The integrity of the purified vacuoles was confirmed by acridine-orange (AO) staining (Supplementary Figure 3). Graphite furnace atomic absorption spectrometry (GFAAS) analysis showed 

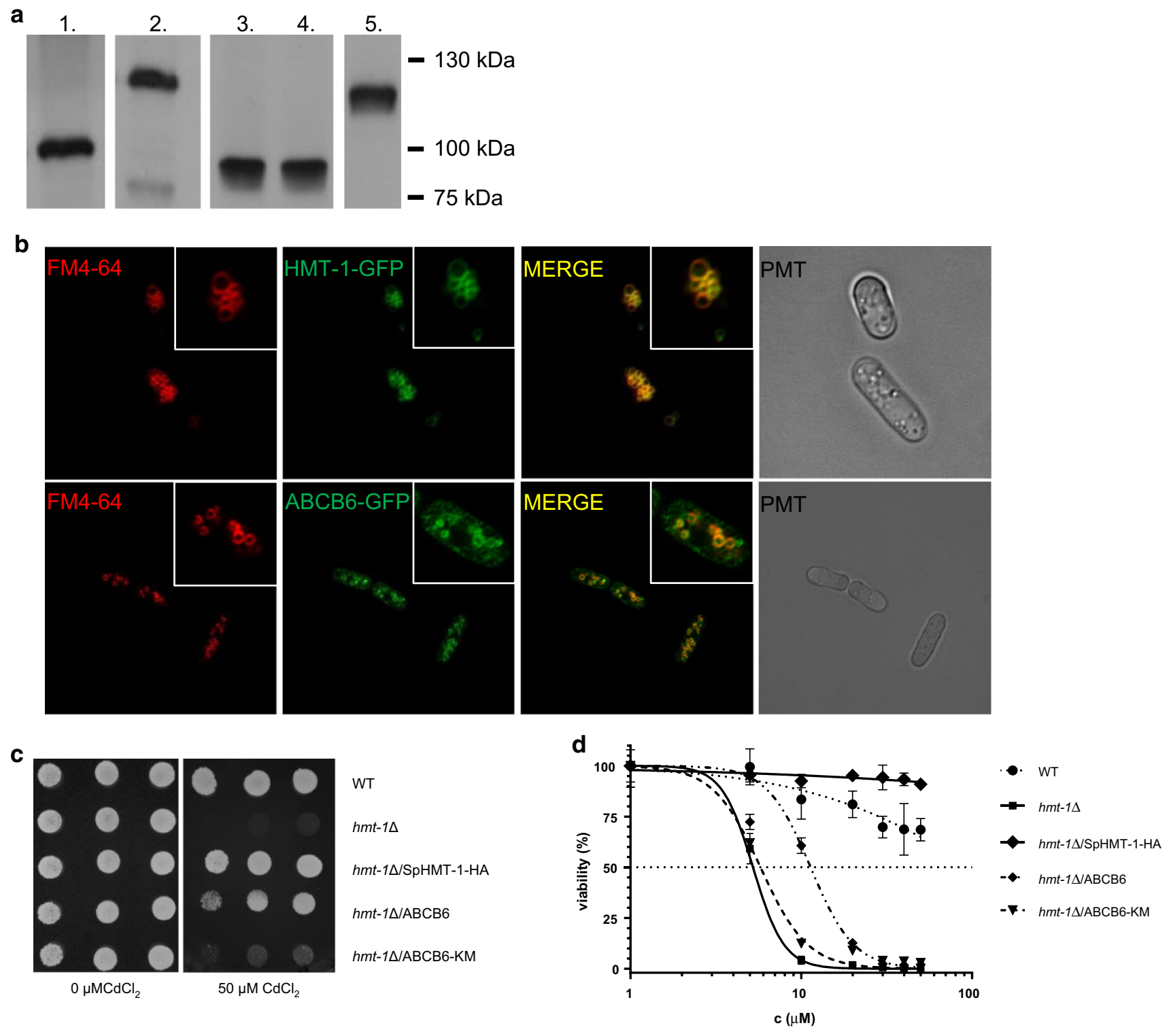

Fig. 1 ABCB6 confers cadmium tolerance in $h m t-1 \Delta$ mutant $S$. pombe. a SDS-PAGE and immunoblot analysis of yeast cells expressing HMT-1-HA (lane 1), HMT-1-GFP (lane 2), ABCB6 (lane 3), ABCB6-KM (lane 4) or ABCB6-GFP (lane 5). Expression of SpHMT-1 was revealed using anti-HA antibody; ABCB6 was labeled by the ABCB6-567 antibody; EGFP tagged proteins were labeled by an anti-EGFP antibody. b ABCB6-GFP (green) localizes to vacuoles (red) of S. pombe. Hmt-1-deleted S. pombe was transformed with pREP1-HMT-1-GFP or ABCB6-GFP; vacuoles were stained with FM 4-64. Insets show individual cells. Scale bar $10 \mu \mathrm{m}$. c Wild-type $S$. pombe cells transformed with empty pREP1 vector (WT); hmt$1 \Delta$ mutant cells transformed with empty pREP1 vector $(h m t-1 \Delta)$,

pREP1-HMT-1-HA (hmt-1 $\Delta$ /SpHMT-1-HA), pREP1-ABCB6 (hmt$1 \Delta / \mathrm{ABCB} 6)$ or pREP1-ABCB6-KM (hmt-1 $\Delta / \mathrm{ABCB} 6-\mathrm{KM})$ were grown overnight to an $A_{600 \mathrm{~nm}}$ of 1.8. Aliquots of the cell suspensions were then serially diluted and spotted onto solid EMM supplemented with adenine, uracil and the indicated concentrations of $\mathrm{CdCl}_{2}$. Colonies were visualized after incubating the plates for 8 days at $30^{\circ} \mathrm{C}$. d Transformants were grown overnight to an $A_{600 \mathrm{~nm}}$ of $0.8-1$. Aliquots of $100-\mu \mathrm{L}$ were inoculated into $2 \mathrm{~mL}$ of the same medium containing $\mathrm{CdCl}_{2}$ at the indicated concentrations. $A_{600 \mathrm{~nm}}$ was measured after growth at $30{ }^{\circ} \mathrm{C}$ for $72 \mathrm{~h}$. Values, expressed as viability (\%), were normalized to untreated control $(n=3)$

that, as compared to the wild type, vacuoles isolated from $h m t$ - 1 -deleted strains contained significantly lower amounts of cadmium, in line with the absence of vacuolar sequestration. Vacuolar cadmium levels were almost fully restored by the expression SpHMT-1 or ABCB6

(Fig. 2). Increased vacuolar accumulation of cadmium was dependent on the functionality of $\mathrm{ABCB} 6$, indicating that the rescue of $h m t-1$-deleted strains was due the ABCB6-mediated vacuolar sequestration of cadmium. 


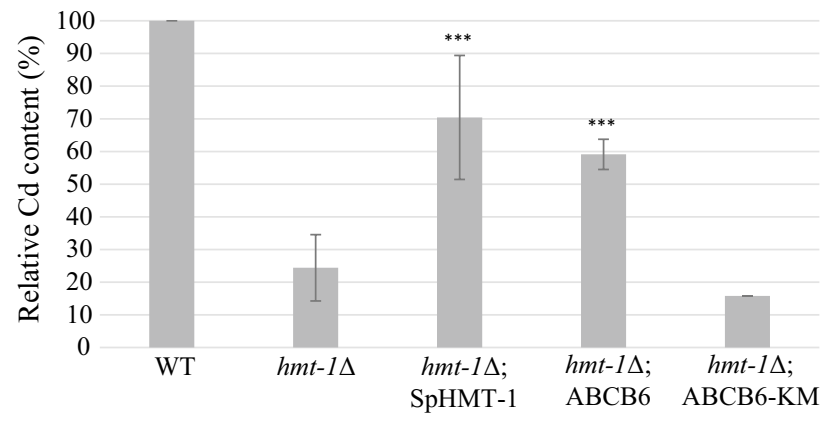

Fig. 2 ABCB6 restores vacuolar Cd levels in $h m t-1 \Delta$ mutant $S$. pombe. Yeast cells lacking SpHMT-1 (hmt-1 $\Delta)$ were engineered to express ABCB6, ABCB6-KM or SpHMT-1. Transformed cells were cultured for $18 \mathrm{~h}$ in growth medium supplemented with $20 \mu \mathrm{M}$ $\mathrm{CdCl}_{2}$. Intact vacuoles were isolated by differential centrifugation; the $\mathrm{Cd}$ content of the isolated vacuoles was quantified by GFAAS. Data show average $\mathrm{Cd}$ levels relative to control calculated from independent experiments $(n=3)$

\section{Human $\mathrm{ABCB} 6$ rescues the $\mathrm{Cd}$ hypersensitivity of $h m t-1$-deleted C. elegans}

CeHMT-1 is expressed in liver-like cells, the coelomocytes, as well as in head and tail neurons, and in the intestinal cells of C. elegans [21]. Crossing of strains expressing CeHMT-1::GFP and ABCB6::mCherry allowed the simultaneous evaluation of the subcellular expression of both proteins. Images obtained with confocal microscopy have indicated that $\mathrm{ABCB} 6$ is expressed in the same tissues as CeHMT-1 (Fig. 3a). To establish the subcellular localization of CeHMT-1 and ABCB6, we performed colocalization experiments using a lysosomal marker [24]. Interestingly, the intracellular organelles corresponding to the sites of CeHMT-1 or ABCB6 expression proved to be distinct from Lysotracker Red-positive lysosomes (Supplementary Figure 4). Next, we crossed phmt-1::hmt-1::gfp and phmt$1:: A B C B 6:: g f p$ worms with pges-1::mCherry::RAB-5,pges$1:: m C h e r r y:: R A B-7$, pges $-1:: m C h e r r y:: R A B-10$ strains [25], which express the fluorescent mCherry protein in different endocytic compartments. Analysis of the transgenic strains showed that CeHMT-1 and ABCB6 partially colocalize with markers of the early, late and basolateral recycling endosomes (mCherry::RAB-5, mCherry::RAB-7 and mCherry::RAB-10, respectively) (Fig. 3b-d).

Since the HMT-1 proteins in S. pombe and C. elegans have been shown to share an orthologous function [20], we investigated whether ABCB6 could also rescue the Cd-sensitive phenotype of an HMT-1-deficient $C$. elegans strain. Adult hermaphrodites were allowed to lay eggs onto NGM plates supplemented with the indicated concentrations of $\mathrm{CdCl}_{2}$, and the progeny reaching adulthood was counted 3 days after hatching at $20{ }^{\circ} \mathrm{C}$ (Fig. 4a). Whereas wild-type and HMT-1-deficient worms were indistinguishable in the absence of heavy metals, the latter were markedly more sensitive to $\mathrm{Cd}$, showing developmental delay, larval arrest and death at early larval stages. As expected, expression of CeHMT-1 provided a full rescue. Remarkably, ABCB6 also restored tolerance to $\mathrm{Cd}$ exposure (Fig. 4a, b).

\section{Human ABCB6 confers Cd tolerance to SNB-19 glioblastoma cells}

The functional relevance of ABCB6 in Cd sensitivity was further evaluated in SNB-19 glioblastoma cells. ABCB6 was overexpressed or silenced by lentiviral transduction (Fig. 5a, Supplementary Figure 5). Immunocytochemical analysis of SNB-19 cells by confocal microscopy confirmed the localization of the endogenous ABCB6 protein in the lysosomal compartment (labeled by LAMP1), and its absence in mitochondria (labeled by AIF) (Fig. 5b, upper panels). Overexpression of ABCB6 also resulted in endolysosomal expression that was clearly distinct from the mitochondrial pattern (Fig. 5b, lower panels). Attenuation of ABCB6 expression sensitized SNB-19 cells to Cd, as compared to cells stably transfected with the scrambled shRNA construct. In line with these results, $\mathrm{ABCB} 6$ overexpression conferred resistance to $\mathrm{Cd}$, showing that $\mathrm{ABCB} 6$ effectively modulates the cadmium tolerance of SNB-19 cells (Fig. 5c).

\section{Discussion}

Cadmium is a nonessential divalent metal ion, posing significant health concerns. Chronic exposure to cadmium is associated with increased mortality and cancer risk [26]. By displacing essential biological metals, cadmium induces oxidative stress and eventual cell death. Organisms have evolved several mechanisms to detoxify and eliminate cadmium from the cells [27]. In Saccharomyces cerevisiae, sequestration of cadmium-glutathione complexes is mediated by ScYCF1, which belongs to the ABCC subfamily [28]. In other species, vacuolar sequestration of cadmium complexes is mediated by HMT-1 proteins, which belong to the ABCB subfamily. Phylogenetic analysis shows that HMT-1s from $S$. pombe, Arabidopsis thaliana, C. elegans and D. melanogaster cluster with ABCB6, together with mitochondrial ATM proteins that are involved in iron-sulfur enzyme biogenesis. ABCB6 was initially named MTABC 3 , because it was considered to be the functional orthologue of Atm1P [4], leading to the erroneous classification of ABCB6 as a mitochondrial protein. Later studies have convincingly demonstrated that the functional orthologue of Atm1P is in fact ABCB7, which is a canonical mitochondrial $\mathrm{ABC}$ transporter localized to the inner mitochondrial membrane [29, 30].

The high degree of sequence and topological similarity between the HMT-1 proteins and ABCB6 suggests an 
evolutionary conserved function, implying ABCB6 in heavy metal resistance [19]. Circumstantial evidence including increased copy numbers, or increased expression in resistant cells [31-33], as well as correlation of gene expression to chemotherapy outcome has implicated ABCB6 in resistance to chemotherapeutic agents [34-36]. Overexpression of rat Abcb6 in LoVo cells conferred tolerance toward copper, suggesting an involvement of rAbcb6 in transition metal homeostasis [16]. There is a direct correlation between arsenic resistance and ABCB6 expression in various human and mouse cell lines, which was interpreted to be based on an ABCB6-mediated increase of cytosolic heme levels, resulting in the reduction of arsenite-induced oxidative stress [37-39]. However, models relying on the mitochondrial function of ABCB6 are difficult to reconcile with the endolysosomal expression pattern shown here and reported by several groups [12-17]. Cell fractionation experiments, images obtained of fixed cells with confocal and electron microscopy, and live cell imaging have repeatedly demonstrated that the endogenous ABCB6 protein is expressed in the endolysosomal system, and not in mitochondria.

Schizosaccharomyces pombe and C. elegans have served as important models for elucidating conserved pathways and processes relevant to human biology and disease. In particular, rescue of mutant phenotypes have established the function of several orthologous human proteins. In the past several years, well-developed genetic, genomic, biochemical and cell biological tools have provided fresh insights into vacuolar protein sorting, organelle homeostasis, autophagy, and stress-related functions of the yeast vacuole, and these insights have often found parallels in mammalian lysosomes $[23,40]$. In this paper, we show that ABCB6 localizes to the same intracellular compartment as HMT-1, performing an overlapping function linked to the intracellular sequestration of metal complexes in both model organisms. Vacuolar localization in yeast was revealed by the expression of differently tagged ABCB6 and SpHMT-1 (Fig. 1b). In C. elegans, $\mathrm{ABCB} 6$ was expressed under the control of the endogenous CeHMT-1 promoter, offering an opportunity to study ABCB6 localization in an intact organism without the burden of artifacts associated with overexpression. In complete agreement with a recent report [41], we find that CeHMT-1 is localized to the endosomal compartment in the intestinal cells of the nematode (Fig. 3). Importantly, ABCB 6 was found in the same intracellular compartment (Fig. 3). Our results confirm recent studies establishing the relevance of the $\mathrm{N}$-terminal domain in the localization of ABCB6 and CeHMT-1 [13, 41]. Determining the subcellular localization of a protein is a key step toward understanding the cellular function of a protein. Although we find that the endogenous $\mathrm{ABCB} 6$ protein is confined to the endolysosomal compartment of SNB-19 glioblastoma cells, it may be argued that the precise intracellular localization can only be established with the discovery of a matching physiological function. In addition to evidence based on imaging of $\mathrm{ABCB} 6$ in native organisms, in this paper we provide functional proof supporting the role of ABCB6 in the vacuolar/ endosomal sequestration of cadmium. First, we show that ABCB6 rescues the Cd-sensitive phenotype of HMT-1-deficient $S$. pombe and C. elegans strains. Second, we show that $\mathrm{ABCB} 6$ function is required for the sequestration of cadmium into HMT-1-deficient yeast vacuoles. Third, we provide evidence that ABCB6 modulates the cadmium sensitivity of human glioblastoma cells. Taken together, these results clearly establish ABCB6 as the human orthologue of HMT-1 proteins.

SpHMT-1 and CeHMT-1 confer cadmium resistance by sequestrating Cd-phytochelatin complexes. Phytochelatins (PCs) are ( $\gamma$-Glu-Cys)n Gly polymers that are restricted to plants and fungi, with the notable exception of $C$. elegans. In animal cells and $S$. cerevisiae, cytoplasmic cadmium is complexed with glutathione (GSH), which is a common chelator involved in cellular response, transport and excretion of metal cations. Importantly, detoxification by CeHMT-1 does not depend on PC synthesis [21], and SpHMT-1 was shown to confer cadmium tolerance in the absence of phytochelatins, but depending on the presence of GSH and ATP, demonstrating that a common, highly conserved mechanism has been selected during evolution [20, 42]. Given the conservation of HMT-1 proteins, we suggest that the ABCB6mediated increase of vacuolar cadmium levels shown in Fig. 2 can be explained by the direct transport of $\left(\mathrm{Cd}-\mathrm{GS}_{2}\right)$ complexes. Remarkably, overexpression of ABCB6 conferred resistance to cadmium in human SNB-19 cells, suggesting that the HMT-1 detoxification pathway is preserved from yeast to human. The contribution of GSH to cadmium detoxification was further suggested by experiments in which SNB-19 cell overexpressing ABCB6 depleted of GSH showed an increased cadmium sensitivity (not shown here). However, no resistance against cadmium has been observed in HeLa cells overexpressing ABCB6 (not shown here). In that respect, $\mathrm{ABCB} 6$ is similar to $\mathrm{ABCC} 1$ (MRP1), whose role in cadmium detoxification appears to be cell specific [42], even though it can functionally complement ScYCF1 in yeast [43]. The reason why the orthologous function of ABCB6 (and ABCC1) does not uniformly manifest in all mammalian cell models is not clear. In mammals, cadmium detoxification relies primarily on metallothioneins, which bind $\mathrm{Cd}$ and also scavenge free radicals generated in oxidative stress [44]. Also, we cannot rule out that the role of ABCB6 in cadmium detoxification of mammalian cells is indirect. Whereas mitochondrial uptake of porphyrins seems improbable, ABCB6 may mediate the sequestration of toxic by-products of $\mathrm{Cd}$-heme interactions into the endolysosomal system [41]. In all examined organisms, overexpression of SpHMT-1 conferred tolerance to cadmium, but not 
a

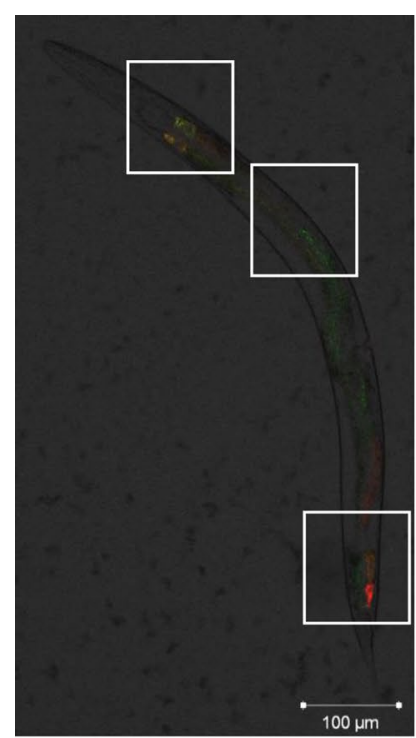

b
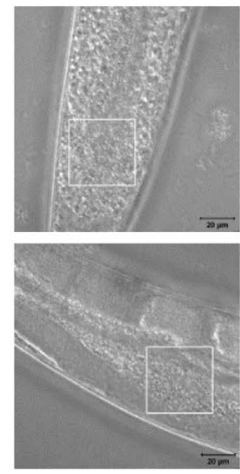

C
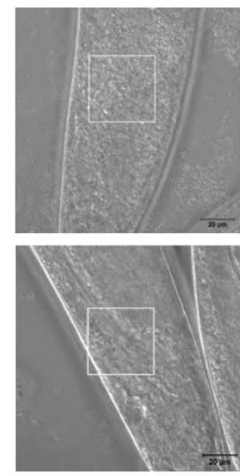

d
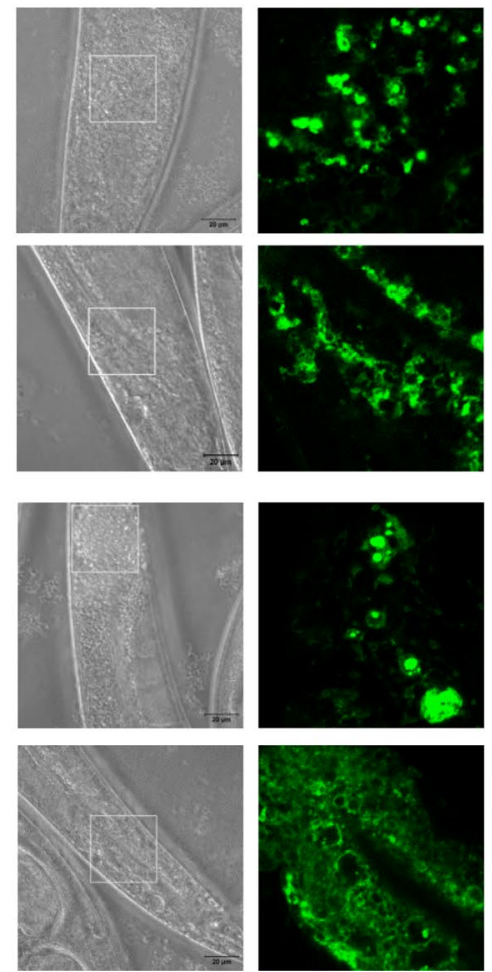
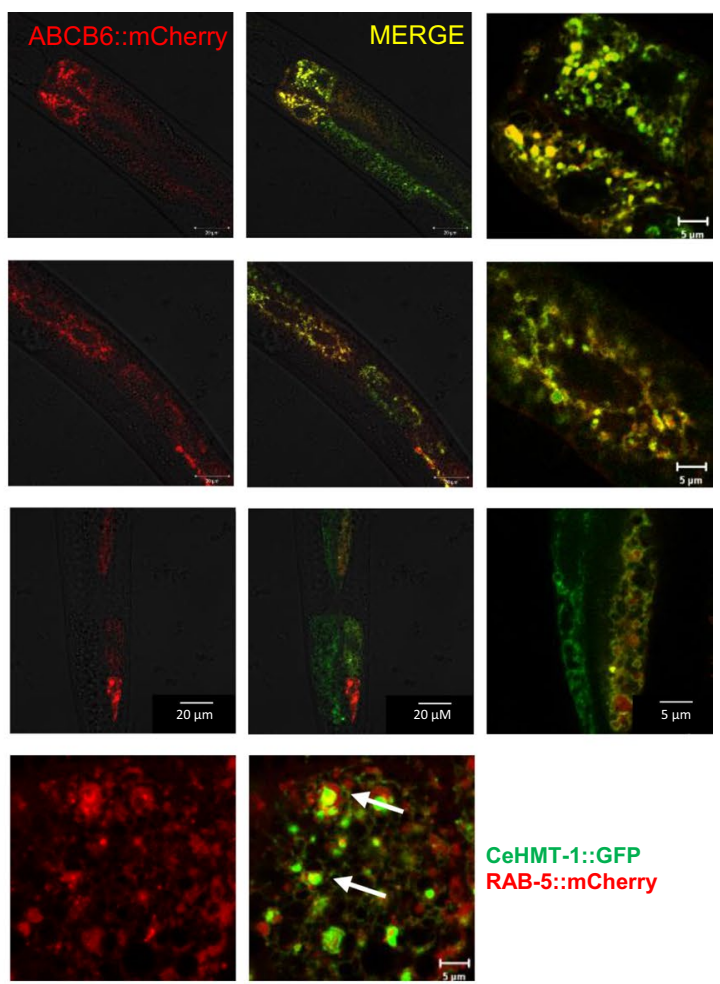

CeHMT-1::GFP

RAB-5::mCherry
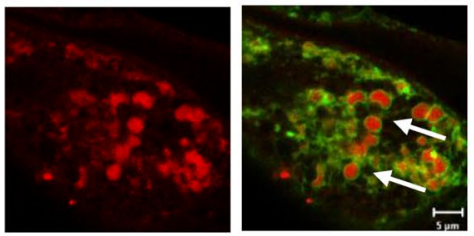

ABCB6::GFP

RAB-5::mCherry
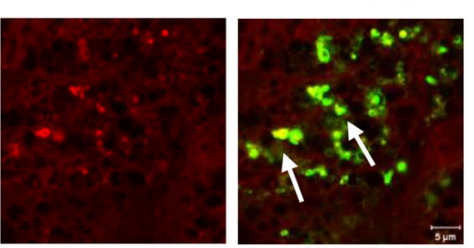

CeHMT-1::GFP

RAB-7::mCherry
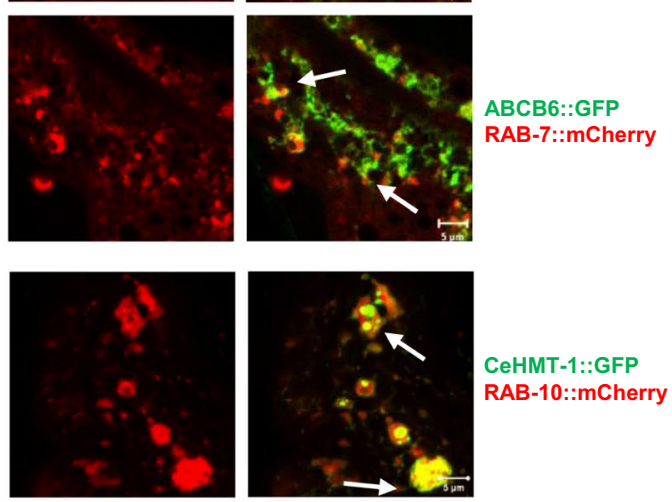

CeHMT-1::GFP

RAB-10::mCherry
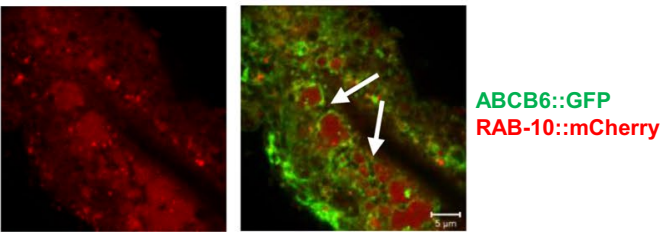
4Fig. 3 CeHMT-1 and ABCB6 show identical localization in nematodes. a Confocal microscopy images of an adult nematode coexpressing ABCB6::mCherry and CeHMT-1::GFP. Crossing of strains expressing CeHMT-1::GFP and ABCB6::mCherry proved that the two transporters are expressed in identical subcellular compartments (scale bar: $100 \mu \mathrm{m}$ ). Boxed areas are shown at a higher magnification (scale bar 20 and $5 \mu \mathrm{m}$ ). Note that the ABCB6::mCherry strain carries the transgene extrachromosomally, resulting in a mosaic expression of ABCB6. b-d CeHMT-1 and ABCB6 partially colocalize with markers of the early, late and basolateral recycling endosomes. Subcellular localization of ABCB6 and CeHMT-1 was determined by confocal microscopy. Strains expressing CeHMT$1::$ GFP or ABCB6::GFP were crossed with worms expressing RAB$5:$ :mCherry (early endosomal marker, b) or RAB-7::mCherry (late and early endosomal marker, c), or RAB-10::mCherry (basolateral recycling endosomes marker, d). The panels show the DIC images (left) the GFP (green) and the mCherry (red) signals and the overlay of the two (right). Scale bar: 20 and $5 \mu \mathrm{m}$

to $\mathrm{Sb}(\mathrm{III}), \mathrm{Ag}(\mathrm{I}), \mathrm{As}(\mathrm{III}), \mathrm{As}(\mathrm{V}), \mathrm{Cu}(\mathrm{II})$, or $\mathrm{Hg}(\mathrm{II})$ [42]; whereas substrates of CeHMT-1 also include As(III) and $\mathrm{Cu}$ (II) [21], indicating how subtle changes in the primary sequence of transporters can fine-tune substrate specificity through evolution [45]. In fission yeast, ABCB6 conferred resistance to $\mathrm{Cd}(\mathrm{II}), \mathrm{As}(\mathrm{III})$, but not to $\mathrm{As}(\mathrm{V})$ or $\mathrm{Cu}(\mathrm{II})$ (Supplementary Figure 2). Preliminary experiments using purified ABCB6 protein have failed to demonstrate stimulation of the ABCB6 ATPase activity by cadmium-GSH complexes (not shown here). Future work, using reconstituted, transport-competent $\mathrm{ABCB} 6$ will be needed to verify the exact nature and extent of ABCB6 substrates.

It also remains to be determined how the evolutionary conserved role in detoxification is manifested in pathological conditions associated with impaired ABCB6 function. Interestingly, lack of $\mathrm{ABCB} 6$ in mice does not result in an overt phenotype $[12,46]$, and ABCB6 deficiency in humans, as observed in Lan-negative individuals, is also without any clinical consequences [5]. On the other hand, disruption of the $A B C B 6$ gene in mice exacerbates porphyria phenotypes in the Fech(m1Pas) mouse model [47], and ABCB6 is a genetic modifier of porphyria [47]. Mutations in the $A B C B 6$ gene were implied in several hereditary diseases ranging from pseudohyperkalemia, coloboma [48], or dyschromatosis universalis hereditaria (DUH) [7, $49,50]$. The pathogenic role of ABCB6 in these conditions is not understood, as there is no obvious overlap between these phenotypes. Pseudohyperkalemia is a dominant red cell trait characterized by increased serum $\left[\mathrm{K}^{+}\right]$in whole blood stored at, or below room temperature (RT), without additional hematological abnormalities [51]. Coloboma is a developmental disorder affecting the eyes, whereas DUH is characterized by asymptomatic hyper- and hypopigmented macules distributed over the body. Based on the results presented in this study, it is tempting to speculate that a common theme in these phenotypes may be disturbed endolysosomal metal homeostasis due to the impaired sequestration of glutathione adducts. The relevance of the endolysosomal compartment in the metabolism/homeostasis of metals is well-known [52]. Thus, the coloboma phenotype may be related to the pathophysiological consequences associated with cadmium exposure, which was shown to alter visually guided behavior in zebrafish as a result of toxicity occurring at the cellular level [53]. Similarly, the ultrastructural abnormalities observed in MNT-1 cells expressing DUH mutant ABCB6 variants may be explained by the impaired intraluminal homeostasis of the maturing early melanosome [12].

The identification of ABCB6 as an HMT-1 orthologue links ABCB6 to heavy metal-related diseases, such as neurodegenerative conditions, dysfunction of the digestive tract and cancer [19]. The pathophysiological relevance of ABCB6 in these conditions remains to be confirmed by studies using relevant disease models. In parallel, heterologous expression of ABCB6 in hmt-1-deficient S. pombe cells may be used as a tool for better understanding the structure and function of ABCB6.

\section{Materials and methods}

\section{Cell culturing}

\section{S. pombe culture conditions and strains}

The $S$. pombe wild-type strain BG_00008 (ade6-M216, ura4-D18, leu1-32) and the $h m t-1$-deleted mutant strain BG_H4691 (ade6-M216, ura4-D18, leu1-32) was a generous gift from R. Lill (Philipps-Universität Marburg). Edinburgh Minimal Medium (EMM Broth, EMM agar and EMM without dextrose) were obtained from Formedium (Hunstanton, UK).

\section{C. elegans culture conditions and strains}

Caenorhabditis elegans strains were maintained at $20{ }^{\circ} \mathrm{C}$ on solid Nematode Growth Medium (NGM) using the E. coli OP50 strain as a food source [54]. The following strains were used: N2 C. elegans wild-type, var. Bristol; DP38 unc-119(ed3)III; VC287 hmt-1(gk161)III; VF31 gfIs 1[phmt-1::hmt-1::gfp, unc-119(+); VF12 hmt1(gk161)III; gfIs1 [phmt-1::hmt-1::GFP, unc-119(+)]. XW1957: qxIs110 (pges-1::mCHERRY::RAB-5); XW1962: qxIs111 (pges-1::mCHERRY::RAB-7); XW9119: qxIs213 (pges-1::mCHERRY::RAB-10) strains were a kind gift from Dr. Xiaochen Wang (Institute of Biophysics, Chinese Academy of Sciences). 
Fig. 4 ABCB6 rescues the Cd-sensitive phenotype of HMT-1-deficient nematodes. a Wild-type (WT), hmt-1-deleted [hmt-1(-)], hmt-1-deleted expressing CeHMT-1::GFP [hmt-1(-); hmt-1::gfp] or ABCB6::GFP [hmt-1(-); $A B C B 6:: g f p]$ adult hermaphrodites were placed individually onto NGM plates supplemented with the indicated concentrations of $\mathrm{Cd}$, and were allowed to lay eggs for $2 \mathrm{~h}$. Shown are the percentages of the progeny reaching adulthood 3 days after hatching (mean of 3 independent trials). ***: Student's $T$ test, $p<0,001$; bars represent $\pm \mathrm{SD}$ ). b Representative pictures of animals grown on plates containing $10 \mu \mathrm{M} \mathrm{CdCl}_{2}, 3$ days after hatching at $20^{\circ} \mathrm{C}$. Heterologous expression of the human ABCB6 protein provided partial rescue, allowing the development of small sized adults, whereas $h m t$-1-deleted animals were arrested at the L2-L3 larval stages

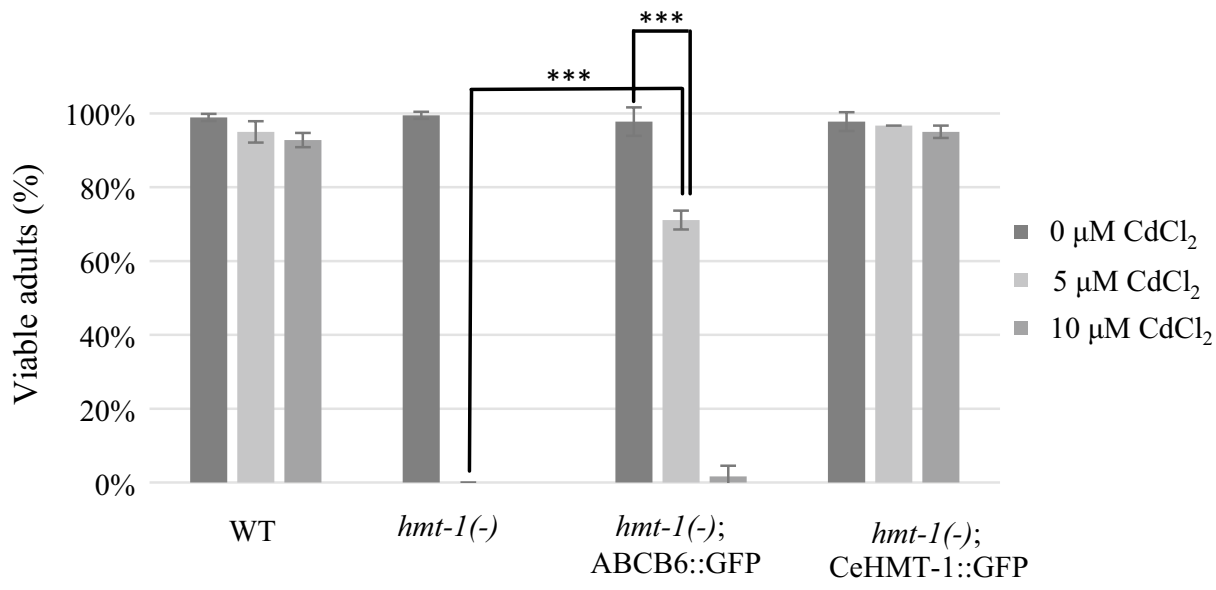

b
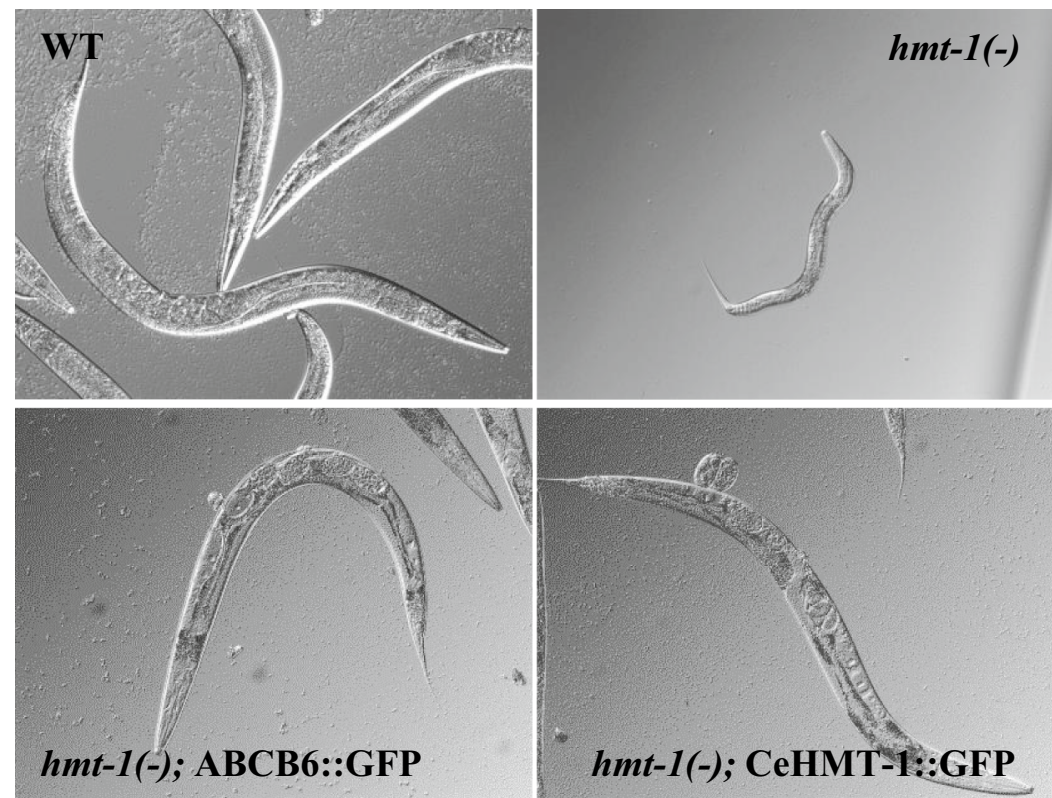

\section{Cell lines}

The SNB-19 glioblastoma cell line was obtained from DSMZ (Germany), HeLa cells were from ATCC. Cells were grown in high glucose DMEM (Gibco 521000-47) supplemented with $10 \%$ FBS, 2 mmol/L glutamine, and 100 units/ $\mathrm{mL}$ penicillin and streptomycin (Life Technologies) at $37{ }^{\circ} \mathrm{C}$ in $5 \% \mathrm{CO}_{2}$. Cells were periodically tested for mycoplasma contamination with the MycoAlert mycoplasma detection Kit (Lonza, Basel, Switzerland).

\section{Molecular cloning of $A B C B 6$ and $h m t-1$ constructs}

\section{Schizosaccharomyces pombe}

Plasmid constructs were amplified in E. coli strain Top10 (Invitrogen, Carlsbad, CA, USA) grown at $37{ }^{\circ} \mathrm{C}$ in liquid Luria-Bertani (LB) medium supplemented with appropriate antibiotics. Hemagglutinin-tagged S. pombe hmt-1 (Z14055) cDNA was synthesized by GenScript (Piscataway, NJ, USA). Site-specific mutation was engineered using the QuikChange site-directed mutagenesis kit (Stratagene, San Diego, CA, USA); the mutation was confirmed by sequencing. The cDNAs encoding $h m t-1$ and $A B C B 6$ variants were subcloned into the pREP1 fission yeast expression vector; pEGFP-N1 (BD Biosciences, Franklin Lakes, NJ, USA) was used for the N-terminal EGFP-tagging of the transporters.

\section{Caenorhabditis elegans}

To generate the phmt-1::ABCB6::gfp and phmt$1:: A B C B 6:: m$ Cherry reporter, codon-optimized $A B C B 6$ cDNA was synthesized by GenScritpt (Piscataway, NJ, USA). After restriction digestion with SphI and XmaI, $A B C B 6$ was subcloned in frame with the $g f p$ sequence of the pPD95.75 vector. A 5' regulatory region of $h m t-1(2.8 \mathrm{~kb}$ 
Fig. 5 Differential expression of ABCB6 modulates $\mathrm{Cd}$ sensitivity of SNB-19 cells. a Overexpression and silencing of ABCB6 in SNB-19 cells. Differential expression of $\mathrm{ABCB} 6$ from total SNB-19 cell lysates was monitored by Western blotting, using the anti-ABCB6 antibody ABCB6-567 [11]. Whole cell lysates of SNB-19 cells $(80 \mu \mathrm{g}$ protein, lane 1$)$, cells overexpressing ABCB6 $(8 \mu \mathrm{g}$ protein, lane 2$)$, and cells transfected with a control (80 $\mu \mathrm{g}$ protein, lane 3 ) or an anti-ABCB6 shRNA vector (80 $\mu \mathrm{g}$ protein, lane 4$)$. $\beta$-Actin is shown for loading control (see Supplementary Figure 5). b ABCB6 is expressed in the endolysosomal compartment of SNB-19 cells. Subcellular localization of endogenous and overexpressed ABCB6 was revealed by immunofluorescence labeling and laser scanning confocal microscopy. Endogenous (upper panels) and overexpressed (lower panels) ABCB6 was visualized using the OSK43 ABCB6 antibody (green); nuclei were labeled with Hoechst 33342 (blue); organelles were labeled with specific markers (red): mitochondria (AIF), lysosomes (LAMP1). Scale bar: $10 \mu \mathrm{m}$. c ABCB6 confers cadmium resistance in SNB-19 glioblastoma cells. SNB-19 cells were engineered to silence $\mathrm{ABCB} 6$ expression by ABCB6 shRNA (ABCB6 sh) or overexpress $\mathrm{ABCB} 6$ (ABCB6). As compared to cells expressing a non-target control shRNA (Ntrg sh) or a control (empty) vector (Vctr), overexpression of ABCB6 confers cadmium resistance, whereas attenuation of ABCB6 levels increases cadmium sensitivity. $\mathrm{IC}_{50}$ values represent means of triplicate measurements (see inset) a
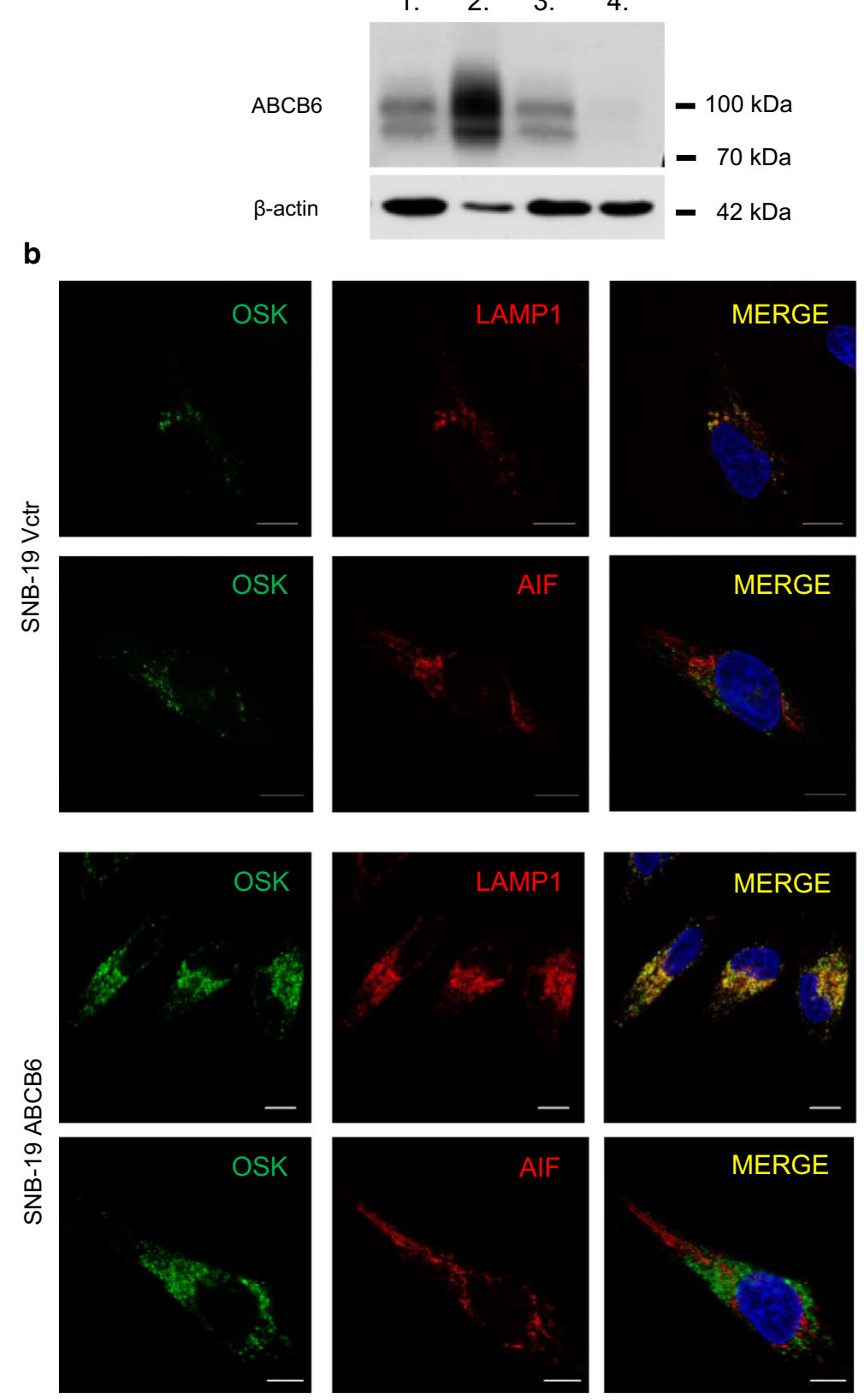

C

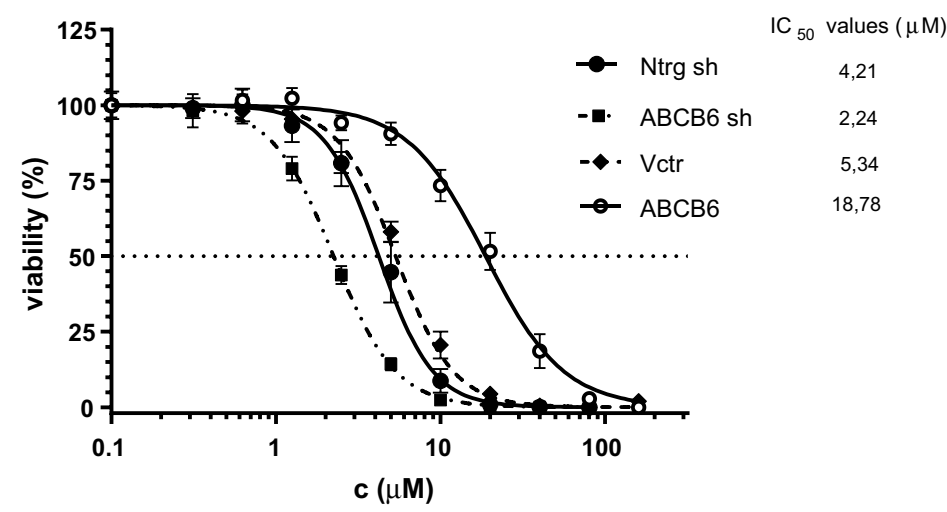


immediately upstream of the start of the $h m t-1$ coding sequence) was PCR-amplified using primer pairs designed to introduce SphI and HpaI restriction enzyme recognition sites at the $5^{\prime}$ and $3^{\prime}$ ends, respectively. The PCR-amplified hmt-1 promoter was subcloned into the pPD95.75-ABCB6EGFP vector. In the case of phmt-1::ABCB6::mCherry, the GFP reporter sequence of pPD95.75-ABCB6-EGFP was changed to the sequence encoding mCherry.

\section{Generation of cell lines}

\section{Yeast transgenic strains}

Yeast cells were grown at $30{ }^{\circ} \mathrm{C}$ in Edinburgh minimal medium (EMM). At an $A_{600 \mathrm{~nm}}$ (OD600) of 1, cells were grown in EMM containing minimal glucose $(5 \mathrm{~g} / \mathrm{L})$. Cells were transformed using the standard lithium acetate procedure [55]. S. pombe transformants were selected for leucine prototrophy in EMM.

\section{C. elegans transgenic strains}

Transgenic C. elegans strains were generated by biolistic transformation using the Biolistic PDS-1000/He particle delivery system (BioRad, Hercules, CA, USA) according to standard methods described by Rieckher et al. [56]. Briefly, 10-10 $\mu \mathrm{g}$ linearized phmt-1::ABCB6::gfp and phmt-1::ABCB6::mCherry reporter plasmids, together with pRH21[unc-119(+)] co-transformation marker plasmid DNA were bombarded onto unc-119(ed3) mutant adult hermaphrodites. Non-Unc transgenic animals exhibiting GFP or mCherry-mediated fluorescence were selected, and the stable integrated strains TTV634: eluIs310 [phmt$1: \because A B C B 6:: g f p+u n c-119(+)] ;$ unc-119(ed3) and TTV677: eluEx383[phmt-1::ABCB6::mCherry + unc-119(+)]; unc119 (ed3) carrying the array extrachromosomally were selected for further analysis. TTV 634 was crossed with $h m t-1(g k l 61)$ to generate TTV 635: $h m t-1(g k 161)$; eluIs 310 [phmt-1::ABCB6::gfp+unc-119(+)].

\section{Human cell lines with enhanced or silenced ABCB6 expression}

$A B C B 6$ knock-down and overexpression were achieved using a self-inactivating lentiviral system, as described previously in [9]. To induce the expression of the shRNA constructs, IPTG $(1 \mathrm{mM})$ was added to the cells for 6 days before additional treatments.

\section{Immunoblotting}

Overnight cultures were grown to $A_{600 \mathrm{~nm}}$ of $1.5-2$. Immunoblotting of human cell lines was performed according to standard protocol. The following primary monoclonal antibodies were used in Western blotting experiments: $\beta$-actin (A1978, Sigma-Aldrich, Saint Louis, MO, USA); antiEGFP (ab184601 Abcam, Cambridge, UK), ABCB6-567 [11], anti-HA antibody, (H6908 Sigma-Aldrich). The HRPdependent luminescence was detected using the enhanced chemiluminescence technique (ECL, Amersham).

\section{Cytotoxicity assays}

\section{Schizosaccharomyces pombe}

Transformed cells were grown in EMM complemented with appropriate supplements. To characterize the chemosensitivity of yeast strains in liquid medium, $100-\mu \mathrm{L}$ overnight cultures $\left(A_{600 \mathrm{~nm}}\right.$ of 0.8$)$ were diluted into 2-mL EMM containing different concentrations of metal compounds (Cd(II) $\mathrm{As}(\mathrm{III}) \mathrm{As}(\mathrm{V}), \mathrm{Sb}$ (III), $\mathrm{Sb}(\mathrm{V}), \mathrm{Hg}(\mathrm{II}), \mathrm{Cu}(\mathrm{II})$, or $\mathrm{Zn}(\mathrm{II}))$. In case of $\mathrm{Sb}$ (III) and $\mathrm{Cu}(\mathrm{II})$, we could not detect toxic concentrations in EMM medium. Cells were then grown at $30^{\circ} \mathrm{C}$. The extent of growth after $72 \mathrm{~h}$ was determined by measuring absorbance at $600 \mathrm{~nm}\left(A_{600 \mathrm{~nm}}\right)$. Viability curves were fitted with Graph Pad Prism 5 software using the sigmoidal dose-response model. To characterize chemosensitivity on agar plates, overnight cultures were diluted in $\operatorname{EMM}\left(A_{600 \mathrm{~nm}}\right.$ of 0.7 ). Colonies were spotted onto plates containing different concentrations of metal compounds and incubated for 6-7 days at $30^{\circ} \mathrm{C}$.

\section{Caenorhabditis elegans}

Heavy metal tolerance of $C$. elegans strains was assayed as described in [19]. Briefly, 8-10 adult worms were allowed to lay eggs for $2 \mathrm{~h}$ at $20{ }^{\circ} \mathrm{C}$ on NGM plates supplemented with the indicated concentrations of $\mathrm{CdCl}_{2} \cdot \mathrm{CdCl}_{2}$ tolerance was quantified by determining the ratio of adult worms and larvae after 3 days at $20^{\circ} \mathrm{C}$. At least 60 animals, derived from 3 parallel plates containing at least 20 animals/category, were counted by light microscopy in 3 independent trials.

\section{Human cell lines}

In cytotoxicity experiments, cells were seeded in $100-\mu \mathrm{L}$ DMEM medium at a density of 4000 cells/well in 96-well plates, and serially diluted drugs were added on the following day in $100-\mu \mathrm{L}$ medium to give the indicated final concentration. Cells were then incubated for $72 \mathrm{~h}$ at $37^{\circ} \mathrm{C}$ in $5 \% \mathrm{CO}_{2}$. Cytotoxicity assays were performed in triplicate. Cell survival was assessed by the PrestoBlue assay (Life Technologies), according to the manufacturer's instructions. Viability curves were fitted with Graph Pad Prism 5 software using the sigmoidal dose-response model. 


\section{Determination of the vacuolar cadmium content}

\section{Vacuole isolation}

Schizosaccharomyces pombe cultures were treated overnight with $20 \mu \mathrm{M} \mathrm{CdCl}_{2}$. Vacuoles were isolated as described in [20], with some modifications. Briefly, 5-mL stationary phase cultures diluted in $25 \mathrm{~mL}$ of EMM were grown for $4-6 \mathrm{~h}$ at $30{ }^{\circ} \mathrm{C}$. Next, $25-\mathrm{mL}$ cultures were diluted in 200-mL EMM medium containing $20-\mu \mathrm{M} \mathrm{CdCl}_{2}$, and the cultures were grown for $18 \mathrm{~h}$ at $30{ }^{\circ} \mathrm{C}$ to an $A_{600 \mathrm{~nm}}$ of 1.5 . Cells were pelleted by centrifugation at $3000 \times g$ for $5 \mathrm{~min}$, and were washed in 50-mL distilled water. After resuspension in 50-mL buffer (20-mM $\beta$-mercaptoethanol, $100-\mathrm{mM}$ Tris- $\mathrm{HCl}$, pH 9.4), cells were incubated for $20 \mathrm{~min}$ at $30{ }^{\circ} \mathrm{C}$ with gentle shaking. Spheroplasts were created by pelleting and resuspending the cells in $20 \mathrm{~mL}$ of digestion medium (1.2-M sorbitol, 10-mM $\beta$-mercaptoethanol, 20-mM potassium phosphate, $50 \mathrm{mg}$ of Zymolyase 20T (ICN) and $100 \mathrm{mg}$ of lysing enzymes from Trichoderma harzianum (SigmaAldrich), $\mathrm{pH}$ 7.5). The suspension was incubated for $2 \mathrm{~h}$ at $30{ }^{\circ} \mathrm{C}$ with gentle shaking, followed by centrifugation at $3000 \times g$ for $5 \mathrm{~min}$. The spheroplasts were washed in $20-\mathrm{mL}$ ice-cold homogenization medium (1.6-M sorbitol, 10-mM MES-Tris, 0.5-mM $\mathrm{MgCl}_{2}, 5$-mM $\beta$-mercaptoethanol, 1 -mM phenylmethylsulfonyl fluoride, and $1 \mu \mathrm{g} / \mathrm{mL}$ each of leupeptin, aprotinin, and pepstatin (protease inhibitor cocktail, Sigma P8340 in 500× dilution), pH 6.9). Pelleted spheroplasts were lysed in the same medium by homogenization in a 5-mL glass Dounce homogenizer. The crude lysate was cleared of cell debris and unbroken cells by centrifugation at $3000 \times g$ for $8 \mathrm{~min}$. The supernatants were collected and the pellet was resuspended in $3.5-\mathrm{mL} \mathrm{HM}$, homogenized again $(30 \times)$, and centrifuged at $3000 \times g$ for $8 \mathrm{~min}$. Supernatants were centrifuged at $13,000 \times g$ at $4{ }^{\circ} \mathrm{C}$ for $35 \mathrm{~min}$. The pellet, containing the partially purified vacuolar fraction was suspended in $1.5 \mathrm{~mL} \mathrm{HM}$, layered onto 1-mL Sucrose step gradient $(40 \% / 50 \%(\mathrm{v} / \mathrm{v}))$, and pelleted at 40,000 rpm using a Beckman Coulter 70.1 Ti rotor at $4{ }^{\circ} \mathrm{C}$ for $1 \mathrm{~h}$. Purified vacuoles were suspended in 3-mL suspension medium (1.6-M sorbitol, 100-mM KCl, 10-mM MES-Tris, 5-mM $\mathrm{MgCl}_{2}$, and protease inhibitors $\mathrm{pH} 6.9$ ), and were centrifuged at $4{ }^{\circ} \mathrm{C}$ at $13,000 \times g$ for $12 \mathrm{~min}$ in an Eppendorf microcentrifuge. The final vacuolar pellet was stored at $-80^{\circ} \mathrm{C}$.

\section{Assessment of integrity of vacuole preparations}

The integrity of the vacuoles was assessed by measuring fluorescence as described in [57]. Acridine orange (AO, Sigma-Aldrich) fluorescence (Supplementary Figure 3) was measured using an Attune Acoustic Focusing cytometer (Applied Biosystems, Life Technologies, Carlsbad, CA, US).

\section{Determination of vacuolar Cd contents}

Vacuolar Cd content was determined by graphite furnace atomic absorption spectrometry (GFAAS). All GFAAS measurements were performed on an Analytik Jena Model ContrAA-700 tandem high-resolution AAS spectrometer (Analytik Jena AG, Jena, Germany), equipped with an MPE-60 autosampler. Each final vacuolar pellet after the isolation was digested in $200-\mu \mathrm{L}$ cc. $(65 \% \mathrm{v} / \mathrm{v}) \mathrm{HNO}_{3}$ for $24 \mathrm{~h}$ at RT. After appropriate dilution, an aliquot of $20 \mu \mathrm{L}$ of each sample was directly dispensed by the autosampler into the pyrolytic graphite coated graphite tube (fitted with a pyrolytically-coated graphite platform) to determine the concentration of $\mathrm{Cd}$ in the isolated vacuoles. The $\mathrm{Cd}$ $228.8018 \mathrm{~nm}$ spectral line was selected for the determinations, with a 3-pixel evaluation of the CCD camera, which corresponds to a resolution of $3.78 \mathrm{pm}$ at this wavelength. The GF heating program consisted of smooth drying (at $100{ }^{\circ} \mathrm{C}$ for $20 \mathrm{~s}, 110^{\circ} \mathrm{C}$ for $5 \mathrm{~s}, 130^{\circ} \mathrm{C}$ for $10 \mathrm{~s}$ ), pyrolysis $\left(350{ }^{\circ} \mathrm{C}\right.$ for $15 \mathrm{~s}, 450{ }^{\circ} \mathrm{C}$ for $10 \mathrm{~s}$ ), atomization/measurement (at $1200{ }^{\circ} \mathrm{C}$ for $3 \mathrm{~s}$ ), and clean-out $\left(2450{ }^{\circ} \mathrm{C}\right.$ for $4 \mathrm{~s}$ ) steps. In these steps, the maximum flow $\left(2 \mathrm{dm}^{3} / \mathrm{min}\right)$ of the GF sheath gas (5.0 Ar, supplier: Messer, Hungary) was applied, except the atomization step, being set to stopped gas flow. Integrated, 3D-absorbance signals were recorded with integration time of $3 \mathrm{~s}$, using iterative spectral background correction. Each measurement data corresponds to an average of three replicate determinations. For quantitative determinations, external standardization was applied by means of setting up five-point calibration curves (range: $0.5-50 \mathrm{ng} /$ $\mathrm{mL} \mathrm{Cd}$; solutions preserved in $2.6 \%$ (v/v) $\mathrm{HNO}_{3}$ ). Recovery was checked by spiking selected samples with $5 \mu \mathrm{L}$ of a Cd standard solution at a concentration of $5 \mathrm{ng} / \mathrm{mL}$ and $50 \mathrm{ng} /$ $\mathrm{mL}$. The precision of the determinations, expressed as relative standard deviation (RSD), was typically below $2.1 \%$, but never worse than 5.3\%. All Cd concentration data were normalized to the protein content of the samples.

\section{Confocal microscopy}

\section{Localization of $\mathrm{ABCB} 6$ in S. pombe}

For the evaluation of intracellular localization of the transporters, $h m t$-1-deleted $S$. pombe was transformed with pREP1-HMT-1-GFP or ABCB6-GFP. Cells were grown to mid-log phase $\left(A_{600 \mathrm{~nm}}\right.$ of $\left.0.5-0.8\right)$ and stained with FM 4-64 as described in [58] with the following modifications. FM 4-64 (T3166 ThermoFischer Scientific Waltham, MA, USA) was dissolved in dimethyl-sulphoxide at a concentration of $1.64 \mathrm{mM}$. Cells were harvested and incubated with $1-\mu \mathrm{L}$ FM 4-64 in 50- $\mu \mathrm{L}$ EMM medium at $30{ }^{\circ} \mathrm{C}$ for 20 min. An aliquot of 1-mL EMM was added and cells were centrifuged at $5000 \times g$ for $5 \mathrm{~min}$ at RT. The cell pellet was resuspended 
in 5-mL EMM, and the suspension was shaken at $30{ }^{\circ} \mathrm{C}$ for $90 \mathrm{~min}$. The total volume was transferred to a centrifuge tube and spun for $5 \mathrm{~min}$ at $5000 \times g$ at RT. The cell pellet was resuspended in 1-mL sterile water, and centrifuged at $5000 \times g$ for $5 \mathrm{~min}$ at RT. Cells were resuspended in $25-\mu \mathrm{L}$ EMM. An aliquot of $7 \mu \mathrm{L}$ was spotted on ConA/polyKcoated (1:1 mixture of $2 \mathrm{mg} / \mathrm{mL}$ concanavalin A and $0.1 \%$ poly-L-lysine) glass slides covered with an $18 \times 18 \mathrm{~mm}^{2}$ cover slip. Confocal images were obtained using a LSM 710 confocal laser scanning microscope (Carl Zeiss AG, Oberkochen, Germany) equipped with a Plan-Apochromat $63 \times / 1.4$ Oil DIC M27 objective. Noise reduction and deconvolution of the images were performed with Huygens Essential (Scientific Volume Imaging B.V.).

\section{Localization of $\mathrm{ABCB} 6$ in C. elegans}

Transgenic strains were grown in normal growth conditions at $20{ }^{\circ} \mathrm{C}$. To test the subcellular co-localization of ABCB6 and CeHMT-1, the phmt-1::ABCB6::mCherry (TTV677) strain was crossed with phmt-1::HMT-1::GFP (VF31) males and the F1 progeny co-expressing both transgenes was examined with a confocal microscope (Zeiss LSM 710, Plan-Apochromat $63 \times / 1.4$ NA Oil DIC M27objective). Lysosomal staining was performed as described in [24]. To determine the subcellular localization of CeHMT-1::GFP and ABCB6::GFP, phmt-1::hmt-1::gfp (VF31) and phmt$1:: A B C B 6: \because g f p$ (TTV634) were crossed with strains expressing different endosomal markers [25], resulting in TTV701 unc-119(ed3)III; eluIs310[phmt-1::ABCB6::gfp + unc119(+)]; qxIs110(Pges-1mCHERRY::RAB-5), TTV702 unc-119(ed3)III; eluIs310[phmt-1::ABCB6::gfp + unc119(+)]; qxIs111(Pges-1mCHERRY::RAB-7), TTV703 unc-119(ed3)III; eluIs310[phmt-1::ABCB6::gfp + unc119(+)]; qXIs213(Pges-1mCHERRY::RAB-10), TTV705 unc-119(ed3)III; gfIs1 [phmt-1::hmt-1::gfp, unc-119(+)]; qxIs110(Pges-1mCHERRY::RAB-5), TTV706 unc119(ed3)III; gfIs1 [phmt-1::hmt-1::gfp, unc-119(+)]; qxIs111(Pges-1mCHERRY::RAB-7), TTV707 unc119(ed3)III; gfIs1[phmt-1::hmt-1::gfp, unc-119(+)]; qxIs213(Pges-1mCHERRY::RAB-10).

\section{Localization of $A B C B 6$ in human cells}

Monoclonal antibodies, dyes and their sources were as follows: Rabbit monoclonal Anti-AIF [D39D2] antibody (\#5318) to apoptosis inducing factor, rabbit monoclonal Anti-EEA1 [C45B10] antibody (\#3288) to early endosome antigen 1, rabbit monoclonal Anti-LAMP1 [D2D11] antibody (\#9091) to lysosome-associated membrane protein 1, secondary goat anti-mouse $\operatorname{IgG}(\mathrm{H}+\mathrm{L}) \mathrm{F}\left(\mathrm{ab}^{\prime}\right)_{2}$ fragment conjugated to Alexa Fluor 647 (\#4410) and secondary goat anti-rabbit $\operatorname{IgG}(\mathrm{H}+\mathrm{L}) \mathrm{F}\left(\mathrm{ab}^{\prime}\right)_{2}$ fragment conjugated to Alexa Fluor 647 (\#4414) were from Cell Signaling Technology. Secondary goat polyclonal antibody to human IgG conjugated to DyLight 488 (ab96907) was purchased from Abcam. Hoechst 33342 (R37605) nuclear counterstain was from Thermo Fisher Scientific. The OSK43 antibody was a kind gift from Dr. Yoshihiko Tani (Japanese Red Cross Osaka Blood Center, Osaka, Japan). SNB-19 cells expressing $\mathrm{ABCB} 6$ variants were plated in an Eppendorf 8-well imaging coverglass (\#0030742036). Hoechst 33342 was applied to the cells for $20 \mathrm{~min}$ prior to fixation; subsequently, cells were rinsed in PBS and fixed for $30 \mathrm{~min}$ in 4\% Paraformaldehyde/PBS at RT. Fixed cells were quenched for 10 min in PBS/100 mM glycine (quenching buffer), washed with PBS and blocked and permeabilized in PBS containing $0.2 \mathrm{mg} / \mathrm{mL}$ BSA $/ 0.1 \%$ Triton X-100/10\% Normal Goat Serum (blocking buffer). Primary antibody was diluted in PBS containing $0.2 \mathrm{mg} / \mathrm{mL}$ BSA/0.1\% Triton X-100/3\% normal goat serum (incubation buffer, IB). Cells were incubated with the primary antibody overnight at $4{ }^{\circ} \mathrm{C}$ in a humified chamber, washed five times in IB, and incubated with the corresponding secondary anti-human, anti-rabbit and anti-mouse antibodies conjugated to Alexa Fluor 488 or Alexa Fluor 647 diluted in IB for 90 min at RT. Samples were washed five times with PBS and subsequently imaged. Confocal images were obtained using a LSM 700 confocal laser scanning microscope (Carl Zeiss, Inc.) equipped with a Plan-Apochromat $63 \times / 1.4$ NA Oil DIC M27 objective. Images were acquired in three channels (blue (Hoechst33342), green (Alexa Fluor 488), red (Alexa Fluor 647)), blue emitting Hoechst 33342 was excited using the $405 \mathrm{~nm}$ laser line, green emitting Alexa Fluor 488 was excited using the $488 \mathrm{~nm}$ laser line and infrared emitting Alexa Fluor 647 was excited using the $633 \mathrm{~nm}$ laser line. Noise reduction and deconvolution of the images were performed with Huygens Essential (Scientific Volume Imaging B.V.).

Acknowledgements Open access funding provided by Austrian Science Fund (FWF). GS was supported by a Momentum Grant of the Hungarian Academy of Sciences. Funding from the Austrian Science Fund (SFB35, GS) is also acknowledged.

\section{Compliance with ethical standards}

Conflict of interest The authors declare no competing interests.

Open Access This article is distributed under the terms of the Creative Commons Attribution 4.0 International License (http://creativeco mmons.org/licenses/by/4.0/), which permits unrestricted use, distribution, and reproduction in any medium, provided you give appropriate credit to the original author(s) and the source, provide a link to the Creative Commons license, and indicate if changes were made. 


\section{References}

1. Borst P, Elferink RO (2002) Mammalian ABC transporters in health and disease. Annu Rev Biochem 71:537-592

2. Sarkadi B, Homolya L, Szakács G, Váradi A (2006) Human multidrug resistance $\mathrm{ABCB}$ and $\mathrm{ABCG}$ transporters: participation in a chemoimmunity defense system. Physiol Rev 86:1179-1236. https://doi.org/10.1152/physrev.00037.2005

3. Szakács G, Váradi A, Ozvegy-Laczka C, Sarkadi B (2008) The role of $\mathrm{ABC}$ transporters in drug absorption, distribution, metabolism, excretion and toxicity (ADME-Tox). Drug Discov Today 13:379-393. https://doi.org/10.1016/j.drudi s.2007.12.010

4. Mitsuhashi N, Miki T, Senbongi H et al (2000) MTABC3, a novel mitochondrial ATP-binding cassette protein involved in iron homeostasis. J Biol Chem 275:17536-17540

5. Helias V, Saison C, Ballif BA (2012) ABCB6 is dispensable for erythropoiesis and specifies the new blood group system Langereis. Nat Genet 44:170-173. https://doi.org/10.1038/ng.1069

6. Koszarska M, Kucsma N, Kiss K et al (2014) Screening the expression of ABCB6 in erythrocytes reveals an unexpectedly high frequency of Lan mutations in healthy individuals. PLoS One 9:e111590. https://doi.org/10.1371/journal.pone.0111590

7. Zhang $\mathrm{C}$, Li D, Zhang J et al (2013) Mutations in ABCB6 cause dyschromatosis universalis hereditaria. J Investig Dermatol 133:2221-2228. https://doi.org/10.1038/jid.2013.145

8. Krishnamurthy PC, Du G, Fukuda Y et al (2006) Identification of a mammalian mitochondrial porphyrin transporter. Nature 443:586-589. https://doi.org/10.1038/nature05125

9. Kiss K, Brozik A, Kucsma N et al (2012) Shifting the paradigm: the putative mitochondrial protein $\mathrm{ABCB} 6$ resides in the lysosomes of cells and in the plasma membrane of erythrocytes. PLoS One. https://doi.org/10.1371/journal.pone.0037378

10. Chavan H, Khan MMT, Tegos G, Krishnamurthy P (2013) Efficient purification and reconstitution of ATP binding cassette transporter B6 (ABCB6) for functional and structural studies. J Biol Chem 288:22658-22669. https://doi.org/10.1074/jbc.M113.48528 4

11. Paterson JK, Shukla S, Black CM et al (2007) Human ABCB6 localizes to both the outer mitochondrial membrane and the plasma membrane. Biochemistry 46:9443-9452. https://doi. org/10.1021/bi700015m

12. Bergam $P$, Reisecker JM, Rakvács $Z$ et al (2018) ABCB6 Resides in melanosomes and regulates early steps of melanogenesis required for PMEL amyloid matrix formation. J Mol Biol. https ://doi.org/10.1016/j.jmb.2018.06.033

13. Kiss K, Kucsma N, Brozik A et al (2015) Role of the N-terminal transmembrane domain in the endo-lysosomal targeting and function of the human ABCB6 protein. Biochem J 467:127-139. https ://doi.org/10.1042/BJ20141085

14. Bagshaw RD, Mahuran DJ, Callahan JW (2005) A proteomic analysis of lysosomal integral membrane proteins reveals the diverse composition of the organelle. Mol Cell Proteom 4:133-143. https ://doi.org/10.1074/mcp.M400128-MCP200

15. Tsuchida M, Emi Y, Kida Y, Sakaguchi M (2008) Human ABC transporter isoform B6 (ABCB6) localizes primarily in the Golgi apparatus. Biochem Biophys Res Commun 369:369-375. https:// doi.org/10.1016/j.bbrc.2008.02.027

16. Jalil YA, Ritz V, Jakimenko A et al (2008) Vesicular localization of the rat ATP-binding cassette half-transporter rAbcb6. Am J Physiol Cell Physiol 294:C579-C590. https://doi.org/10.1152/ ajpcell.00612.2006

17. Della Valle MC, Sleat DE, Zheng H et al (2011) Classification of subcellular location by comparative proteomic analysis of native and density-shifted lysosomes. Mol Cell Proteom 10:M110 006403. https://doi.org/10.1074/mcp.M110.006403

18. Ortiz DF, Kreppel L, Speiser DM et al (1992) Heavy metal tolerance in the fission yeast requires ATP-binding cassette-type vacuolar membrane transporter. EMBO J 11:3491-3499

19. Schwartz MS, Benci JL, Selote DS et al (2010) Detoxification of multiple heavy metals by a half-molecule $\mathrm{ABC}$ transporter, HMT-1, and coelomocytes of Caenorhabditis elegans. PLoS One 5:e9564. https://doi.org/10.1371/journal.pone.0009564

20. Sooksa-Nguan T, Yakubov B, Kozlovskyy VI et al (2009) Drosophila ABC transporter, DmHMT-1, confers tolerance to cadmium. DmHMT-1 and its yeast homolog, SpHMT-1, are not essential for vacuolar phytochelatin sequestration. J Biol Chem 284:354-362. https://doi.org/10.1074/jbc.M806501200

21. Vatamaniuk OK, Bucher EA, Sundaram MV, Rea PA (2005) CeHMT-1, a putative phytochelatin transporter, is required for cadmium tolerance in Caenorhabditis elegans. J Biol Chem 280:23684-23690. https://doi.org/10.1074/jbc.M503362200

22. Mendoza-Cózatl DG, Zhai Z, Jobe TO et al (2010) Tonoplastlocalized Abc2 transporter mediates phytochelatin accumulation in vacuoles and confers cadmium tolerance. J Biol Chem 285:40416-40426. https://doi.org/10.1074/jbc.M110.155408

23. Takegawa K, Iwaki T, Fujita Y et al (2003) Vesicle-mediated protein transport pathways to the vacuole in Schizosaccharomyces pombe. Cell Struct Funct 28:399-417. https://doi.org/10.1247/ csf.28.399

24. O'Rourke EJ, Soukas AA, Carr CE, Ruvkun G (2009) C. elegans major fats are stored in vesicles distinct from lysosome-related organelles. Cell Metab 10:430-435. https://doi.org/10.1016/j. cmet.2009.10.002

25. Chen B, Jiang Y, Zeng S et al (2010) Endocytic sorting and recycling require membrane phosphatidylserine asymmetry maintained by TAT-1/CHAT-1. PloS Genet $6:$ e1001235. https://doi. org/10.1371/journal.pgen.1001235

26. Tchounwou PB, Yedjou CG, Patlolla AK, Sutton DJ (2012) Heavy metals toxicity and the environment. EXS 101:133-164. https:// doi.org/10.1007/978-3-7643-8340-4_6

27. Thévenod F (2010) Catch me if you can! Novel aspects of cadmium transport in mammalian cells. Biometals 23:857-875. https ://doi.org/10.1007/s10534-010-9309-1

28. Li Z-S, Lu Y-P, Zhen R-G et al (1997) A new pathway for vacuolar cadmium sequestration in Saccharomyces cerevisiae: YCF1catalyzed transport of bis(glutathionato)cadmium. Proc Natl Acad Sci 94:42-47. https://doi.org/10.1073/pnas.94.1.42

29. Csere P, Lill R, Kispal G (1998) Identification of a human mitochondrial ABC transporter, the functional orthologue of yeast Atm1p. FEBS Lett 441:266-270

30. Pondarré C, Antiochos BB, Campagna DR et al (2006) The mitochondrial ATP-binding cassette transporter Abcb7 is essential in mice and participates in cytosolic iron-sulfur cluster biogenesis. Hum Mol Genet 15:953-964. https://doi.org/10.1093/hmg/dd101 2

31. Annereau J-P, Szakács G, Tucker CJ et al (2004) Analysis of ATPbinding cassette transporter expression in drug-selected cell lines by a microarray dedicated to multidrug resistance. Mol Pharmacol 66:1397-1405. https://doi.org/10.1124/mol.104.005009

32. Januchowski R, Zawierucha P, Andrzejewska M et al (2013) Microarray-based detection and expression analysis of $\mathrm{ABC}$ and SLC transporters in drug-resistant ovarian cancer cell lines. Biomed Pharmacother 67:240-245. https://doi.org/10.1016/j. biopha.2012.11.011

33. Yasui K, Mihara S, Zhao C et al (2004) Alteration in copy numbers of genes as a mechanism for acquired drug resistance. Cancer Res 64:1403-1410. https://doi.org/10.1158/0008-5472. CAN-3263-2 
34. Park S, Shimizu C, Shimoyama T et al (2006) Gene expression profiling of ATP-binding cassette (ABC) transporters as a predictor of the pathologic response to neoadjuvant chemotherapy in breast cancer patients. Breast Cancer Res Treat 99:9-17

35. Varatharajan S, Abraham A, Karathedath S et al (2017) ATPbinding casette transporter expression in acute myeloid leukemia: association with in vitro cytotoxicity and prognostic markers. Pharmacogenomics 18:235-244. https://doi.org/10.2217/ pgs-2016-0150

36. Szakács G, Annereau J-P, Lababidi S et al (2004) Predicting drug sensitivity and resistance: profiling $\mathrm{ABC}$ transporter genes in cancer cells. Cancer Cell 6:129-137. https://doi.org/10.1016/j. ccr.2004.06.026

37. Chavan H, Oruganti M, Krishnamurthy P (2011) The ATP-binding cassette transporter ABCB6 is induced by arsenic and protects against arsenic cytotoxicity. Toxicol Sci Off J Soc Toxicol 120:519-528. https://doi.org/10.1093/toxsci/kfr008

38. Córdova EJ, Martínez-Hernández A, Uribe-Figueroa L et al (2014) The NRF2-KEAP1 pathway is an early responsive gene network in arsenic exposed lymphoblastoid cells. PLoS One 9:e88069. https://doi.org/10.1371/journal.pone.0088069

39. Zhang Y, Dai C, Yuan C et al (2017) Establishment and characterization of arsenic trioxide resistant KB/ATO cells. Acta Pharm Sin B 7:564-570. https://doi.org/10.1016/j.apsb.2017.04.001

40. Li SC, Kane PM (2009) The yeast lysosome-like vacuole: endpoint and crossroads. Biochim Biophys Acta BBA Mol Cell Res 1793:650-663. https://doi.org/10.1016/j.bbamcr.2008.08.003

41. Kim S, Sharma AK, Vatamaniuk OK (2018) N-terminal extension and C-terminal domains are required for ABCB6/HMT-1 protein interactions, function in cadmium detoxification, and localization to the endosomal-recycling system in Caenorhabditis elegans. Front Physiol 9:885. https://doi.org/10.3389/fphys.2018.00885

42. Prévéral S, Gayet L, Moldes C et al (2009) A common highly conserved cadmium detoxification mechanism from bacteria to humans: heavy metal tolerance conferred by the ATP-binding cassette $(\mathrm{ABC})$ transporter SpHMT1 requires glutathione but not metal-chelating phytochelatin peptides. J Biol Chem 284:49364943. https://doi.org/10.1074/jbc.M808130200

43. Tommasini R, Evers R, Vogt E et al (1996) The human multidrug resistance-associated protein functionally complements the yeast cadmium resistance factor 1. Proc Natl Acad Sci USA 93:6743-6748

44. Sabolić I, Breljak D, Škarica M, Herak-Kramberger CM (2010) Role of metallothionein in cadmium traffic and toxicity in kidneys and other mammalian organs. Biometals 23:897-926. https://doi. org/10.1007/s10534-010-9351-z

45. Gokirmak T, Campanale JP, Shipp LE et al (2012) Localization and substrate selectivity of sea urchin multidrug (MDR) efflux transporters. J Biol Chem. https://doi.org/10.1074/jbc. M112.424879

46. Ulrich DL, Lynch J, Wang Y et al (2012) ATP-dependent mitochondrial porphyrin importer ABCB6 protects against phenylhydrazine toxicity. J Biol Chem 287:12679-12690. https ://doi.org/10.1074/jbc.M111.336180

47. Fukuda Y, Cheong PL, Lynch J et al (2016) The severity of hereditary porphyria is modulated by the porphyrin exporter and Lan antigen ABCB6. Nat Commun 7:12353. https://doi.org/10.1038/ ncomms 12353

48. Wang L, Wang L, He F et al (2012) ABCB6 mutations cause ocular coloboma. Am J Hum Genet 90:40-48. https://doi. org/10.1016/j.ajhg.2011.11.026

49. Liu H, Li Y, Hung KKH et al (2014) Genome-wide linkage, exome sequencing and functional analyses identify ABCB6 as the pathogenic gene of dyschromatosis universalis hereditaria. PLoS One 9:e87250. https://doi.org/10.1371/journal.pone.00872 50

50. Cui Y-X, Xia X-Y, Zhou Y et al (2013) Novel mutations of ABCB6 associated with autosomal dominant dyschromatosis universalis hereditaria. PLoS One 8:e79808. https://doi.org/10.1371/ journal.pone.0079808

51. Andolfo I, Alper SL, Delaunay J et al (2013) Missense mutations in the ABCB6 transporter cause dominant familialpseudohyperkalemia. Am J Hematol 88:66-72. https://doi.org/10.1002/ ajh. 23357

52. Polishchuk EV, Polishchuk RS (2016) The emerging role of lysosomes in copper homeostasis. Metallomics 8:853-862. https:// doi.org/10.1039/C6MT00058D

53. LeFauve MK, Connaughton VP (2017) Developmental exposure to heavy metals alters visually-guided behaviors in zebrafish. Curr Zool 63:221-227. https://doi.org/10.1093/cz/zox017

54. Brenner S (1974) The genetics of Caenorhabditis elegans. Genetics 77:71-94

55. Matsuo Y, Asakawa K, Toda T, Katayama S (2006) A rapid method for protein extraction from fission yeast. Biosci Biotechnol Biochem 70:1992-1994. https://doi.org/10.1271/bbb.60087

56. Rieckher M, Kourtis N, Pasparaki A, Tavernarakis N (2009) Transgenesis in Caenorhabditis elegans. In: Cartwright EJ (ed) Transgenesis techniques. Humana Press, New York, pp 21-39

57. Rodrigues J, Silva RD, Noronha H et al (2013) Flow cytometry as a novel tool for structural and functional characterization of isolated yeast vacuoles. Microbiol U K 159:848-856. https://doi. org/10.1099/mic.0.062570-0

58. Vida TA, Emr SD (1995) A new vital stain for visualizing vacuolar membrane dynamics and endocytosis in yeast. J Cell Biol 128:779-792

Publisher's Note Springer Nature remains neutral with regard to jurisdictional claims in published maps and institutional affiliations. 